\title{
Colorimetric Detection of Mercury(II) Ion in Aqueous Solution Using Silver Nanoparticles
}

\author{
M. Lutfi Firdaus, $* 1 \dagger$ Ikka Fitriani, ${ }^{* 1}$ Santhy Wyantuti, $* 2$ Yeni W. HartatI, ${ }^{2}$ Renat Khaydarov, $* 3$ \\ Jason A. MCalister, ${ }^{* 4}$ Hajime OBata, ${ }^{* 5}$ and Toshitaka GaMo $* 5$ \\ *1 Graduate School of Science Education, University of Bengkulu, Bengkulu 38371, Indonesia \\ *2 Department of Chemistry, University of Padjadjaran, Bandung 40132, Indonesia \\ *3 Institute of Nuclear Physics, Uzbek Academy of Sciences, Tashkent 100214, Uzbekistan \\ *4 Department of Earth, Ocean, and Atmospheric Sciences, University of British Columbia, BC V6T 1Z4, Canada \\ *5 Atmosphere and Ocean Research Institute, The University of Tokyo, Chiba 277-8564, Japan
}

\begin{abstract}
Novel green-chemistry synthesis of silver nanoparticles (AgNPs) is introduced as a low-cost, rapid and easy-to-use analytical method for mercury ion detection. Aqueous fruit extract of water apple (Syzygium aqueum) was used for the first time as bioreductant to synthesize stable AgNPs. The prepared AgNPs have a yellowish-brown color with a surface plasmon resonance peak at $420 \mathrm{~nm}$. The addition of $\mathrm{Hg}$ (II) ions then changes the AgNPs color to colorless. The color change was in proportion to the concentration of $\mathrm{Hg}(\mathrm{II})$ ions. The presence of other metal ions in the system was also evaluated. The proposed method shows good selectivity and sensitivity towards $\mathrm{Hg}(\mathrm{II})$ ions. Using UV-visible spectrophotometry, the detection limit of the developed method was $8.5 \times 10^{-7} \mathrm{M}$. The proposed method has been successfully applied for determination of $\mathrm{Hg}$ (II) ions in tap and lake water samples with precision better than $5 \%$.
\end{abstract}

Keywords Mercury detection, colorimetry, Syzygium aqueum, silver nanoparticles, surface plasmon resonance

(Received January 25, 2017; Accepted March 27, 2017; Published July 10, 2017)

\section{Introduction}

The advancement of real-time, rapid and cost-effective tools for analyzing mercury $(\mathrm{Hg})$ concentrations in environmental samples is very important due to seriousness of mercury toxicity to humans. Toxic effects of mercury include damage to the nervous system, brain, kidneys and lungs. ${ }^{1,2}$ Mercury is a heavy metal, which, in the metallic zero oxidation state, $\operatorname{Hg}(0)$, exists as a vapor or as a liquid metal. In the mercurous state, $\mathrm{Hg}(\mathrm{I})$, it exists as inorganic salts, and in its mercuric state, $\mathrm{Hg}$ (II), may form either inorganic salts or organometal compounds. Among the three groups, dimethylmercury, $\mathrm{Hg}\left(\mathrm{CH}_{3}\right)_{2}$, is the most toxic compound because of its mobility in living systems and ability to cross cell membranes..$^{2-4}$ The sources of mercury include natural degassing of the earth's surface, coal-burning power plants and gold-mining operations. ${ }^{5}$ Mercury does not break down in the environment, and thus is a persistent pollutant. The consumption of fish and shellfish is the most significant pathway of mercury exposure in humans, due to bioaccumulation of methylmercury through the food web. ${ }^{3}$

Various analytical methods have been developed to monitor mercury concentrations in environmental samples, including cold vapor atomic fluorescence (CV-AFS $)^{6}$ and inductively coupled plasma mass spectrometry (ICP-MS). ${ }^{7,8}$ However, these instrumentation methods are expensive, laborious and timeconsuming. In regards to these drawbacks, methods providing

$\dagger$ To whom correspondence should be addressed.

E-mail: lutfi@unib.ac.id low-cost and rapid detection of mercury in the environment using silver nanoparticles (AgNPs) and gold nanoparticles (AuNPs) as colorimetric sensors are advantageous. These analytical methods transform analytes concentration into color changes, which have the potential for simple in-the-field qualitative and quantitative applications through colorimetric or naked-eye detection. Thus, colorimetric methods using AgNPs and AuNPs have shown to be promising tools for monitoring the level of mercury, especially in highly polluted areas. ${ }^{9-13}$

Nanotechnology is a rapidly growing field for producing tools using particles on the order of about a nanometer $\left(10^{-9} \mathrm{~m}\right)$ in scale. Nanotechnology offers significant improvements to benefit the life sciences, healthcare, and industrial technology. ${ }^{14}$ An eco-friendly process for the synthesis of metallic nanoparticles is an important step in nanotechnology. Recently, the use of eco-friendly nanotechnology for the development of selective and sensitive detection methods in the analytical and biological sciences has become increasingly important. ${ }^{15-17}$ Particularly, colorimetric sensors have a distinct advantage due to their simplicity, rapidity, high selectivity, and ease of use, including allowing real-time qualitative and quantitative analysis. ${ }^{18,19}$ Fruit extracts, which have heteroaromatic rings and hydroxyl, carbonyl and carboxyl groups, act as reducing as well as stabilizing agents in AgNP synthesis. ${ }^{20,21}$ Here we present and discuss the first report of AgNP biosynthesis using water apple (Syzygium aqueum) fruit extract as a replacement to toxic chemical substances and its application for $\mathrm{Hg}$ (II) colorimetric detection. Water apple belongs to a species of brush cherry tree and is found in tropical countries. It can be harvested from the July to December, and thus it is easily utilized. 


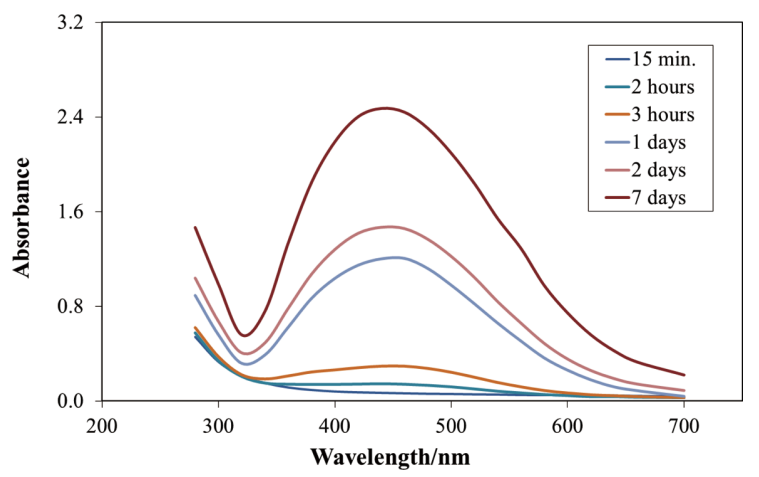

Fig. 1 Time-dependent UV-visible spectra of AgNP formation at room temperature and without sunlight irradiation, with 1:5 volume ratio of fruit extract to $\mathrm{AgNO}_{3}$ solution, resulting in a broad peak absorbance at $440 \mathrm{~nm}$. The highest absorbance of synthesized AgNPs was formed after 7 days.

\section{Experimental}

\section{Materials}

Silver nitrate, as a precursor for AgNPs, salts of additional cations tested, and all other chemicals were supplied by Merck Ltd. (Darmstadt, Germany). Fresh fruits of water apple were obtained from a local market in Indonesia. All glassware was washed with detergent $(5 \%), 4 \mathrm{M} \mathrm{HCl}$, and water before use. Double-distilled deionized water was used throughout the experiments.

\section{Instruments}

Absorption spectra of the synthesized AgNPs were measured using a UV-visible biospectrometer (Eppendorf, Germany). Fourier transform infrared (FTIR) spectra were obtained on a Prestige 21 (Shimadzu, Japan). The morphology and size of AgNPs were analyzed using a scanning electron microscope (SEM) type EVO MA10 (Carl Zeiss, Germany). A Canon 30D digital camera (Tokyo, Japan) was used to record pictures.

\section{Biosynthesis of silver nanoparticles}

Fresh water apple fruits were cleaned and washed with water to remove dust. Fifty grams of fine-cut fruit were boiled with $50 \mathrm{~mL}$ of water at $80^{\circ} \mathrm{C}$ for $15 \mathrm{~min}$. The boiled water was then separated from the remaining small solids by filtration through Whatman filter paper to obtain the extract. The fresh extract was prepared daily to obtain consistent and accurate results.

An aqueous solution of $1 \mathrm{mM} \mathrm{AgNO}_{3}$ was prepared in Erlenmeyer flasks and the appropriate volume of fruit extract was added to reduce $\operatorname{Ag}(\mathrm{I})$ ions to colloidal metallic $\operatorname{Ag}(0)$ nanoparticles under natural sunlight irradiation for $30 \mathrm{~min}$. Additionally, a control of $\mathrm{AgNO}_{3}$ and fruit extract mixture was kept at room temperature without sunlight irradiation. Biosynthesis of AgNPs was optimized by testing different ratios of fruit extracts and $\mathrm{AgNO}_{3}$ solution. The volume ratios of fruit extract to $\mathrm{AgNO}_{3}$ were 1:5, 1:1, 2:1, and 5:1. An aliquot of the mixture was sampled at given time points to monitor the progress of AgNP biosynthesis by UV-vis spectrophotometry. The $\mathrm{pH}$ of the reaction was maintained at $4.5 \pm 0.2$. UV-vis spectra were recorded from 270 to $700 \mathrm{~nm}$ at a resolution of $1 \mathrm{~nm}$ and further characterizations were conducted by FTIR and SEM. For FTIR analysis, a small amount of solution containing fruit extract (or AgNPs) was poured into a petri-dish and left in

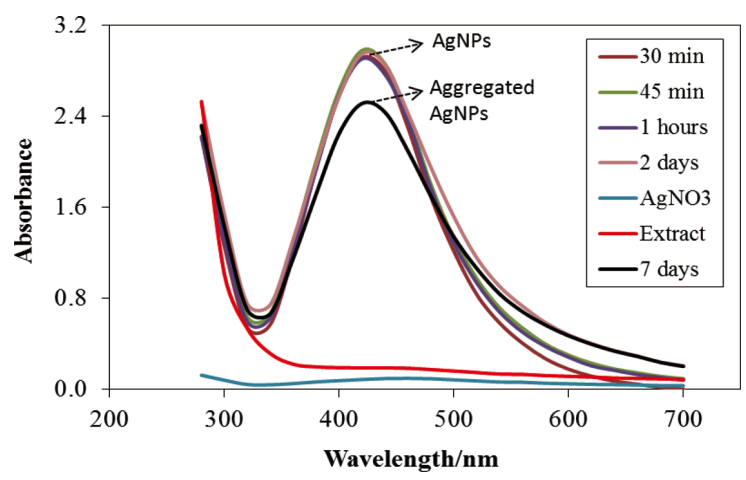

Fig. 2 Time-dependent UV-visible spectra of AgNP formation with sunlight irradiation and 2:1 volume ratio of fruit extract to $\mathrm{AgNO}_{3}$ solution, resulting in a sharp peak absorbance at $420 \mathrm{~nm}$. AgNPs were formed after $30 \mathrm{~min}$ and aggregated after 7 days at the same wavelength $(420 \mathrm{~nm})$ of peak absorbance.

the oven at $250^{\circ} \mathrm{C}$ for $24 \mathrm{~h}$ until all of the solvent evaporated. The dried fruit extract (or AgNPs) was mixed with $\mathrm{KBr}$ and pressed to a plate for measurement. All of the FTIR spectra were measured at a resolution of $4 \mathrm{~cm}^{-1}$ with 40 scans.

\section{Colorimetric detection of mercury ions}

For colorimetric detection of $\mathrm{Hg}$ (II) ions in aqueous samples, $5 \mathrm{~mL}$ aliquots of freshly prepared AgNPs were transferred to transparent glass vials, and then a known concentration of $\mathrm{Hg}(\mathrm{II})$ and other metal ions ( $\mathrm{Al}, \mathrm{Co}, \mathrm{Cr}, \mathrm{Cu}, \mathrm{Fe}, \mathrm{Mg}, \mathrm{Mn}, \mathrm{Na}$, $\mathrm{Ni}, \mathrm{Pb}$ and $\mathrm{Zn}$ ) were added into the vials. Subsequently, the absorption spectra were recorded using a UV-visible spectrophotometer after appropriate incubation and photographs of the solutions were taken with a camera. For real water analysis, tap and lake water samples were collected in the nearby area of our campus and filtered prior to use. Standards and samples were prepared under identical conditions and all experiments were repeated three times to confirm reproducibility.

\section{Results and Discussion}

Effect of sunlight irradiation and fruit extract concentration on AgNP formation

Chemical reductants such as $\mathrm{NaBH}_{4}$ have been widely used to reduce $\mathrm{Ag}(\mathrm{I})$ to $\mathrm{Ag}(0)$ in producing $\mathrm{AgNPs}$. In addition, fossilorigin energy in various forms has also been used to accelerate the production of AgNPs. In this report, we propose a green route to synthesize AgNPs using an aqueous extract of water apple fruit as a bioreductant coupled with sunlight irradiation as a renewable energy to speed up the synthesis reaction. This less hazardous synthesis protocol coupled with energy efficiency are both important principles and practices of green chemistry. ${ }^{22}$ Figures 1 and 2 show the results of AgNP formation without and with sunlight irradiation, respectively, as measured by UV-visible spectra absorbance. Without the assistance of sunlight irradiation AgNPs started to form from a 1:5 ratio of fruit extract to $\mathrm{AgNO}_{3}$ solution after 1 day of incubation, with increasing synthesis at day 2 and day 7 (Fig. 1). With 2:1 and 5:1 ratios of fruit extract to $\mathrm{AgNO}_{3}$ solution AgNPs were not formed in the absence of sunlight even after 7 days of incubation.

In contrast, with the assistance of sunlight irradiation, the formation of AgNPs occured after only 30 min incubation time. While every ratio of fruit extract to $\mathrm{AgNO}_{3}$ produced AgNPs 
(a)<smiles>[Y19][CH][C@@H](CO)[C@H]1OC(=O)C(=O)C1=O</smiles>

Ascorbate ion<smiles>O=C1OC(C(O)CO)C(O)=C1O</smiles>

Ascorbic acid<smiles>COC1=C([Hg]C)C(C(O)CO)OC1=O</smiles>

Ascorbate radical<smiles>O=C1OC([C@@H](O)CO)C(=O)C1=O</smiles>

Dehydroascorbate

Fig. 3 Proposed reaction mechanisms for AgNP synthesis without (a) and with sunlight irradiation (b). The latter has a faster reaction time through a free radical step.

when exposed to sunlight, the best ratio of $2: 1$ is shown in Fig. 2. The optimum condition as shown in its very intense absorbance and narrow peak suggests that using a 2:1 concentration of fruit extract to $\mathrm{AgNO}_{3}$, it is likely that all of $\operatorname{Ag}(\mathrm{I})$ was reduced to $\operatorname{Ag}(0)$. The as-prepared AgNP colloidal solution was yellowish-brown and transparent, indicating good dispersity of AgNPs in water. The UV-visible absorption spectra of AgNPs show an absorption peak at $420 \mathrm{~nm}$ due to the surface plasmon excitation..$^{23,24}$

From these results, it is determined that sunlight-assisted photochemical reaction accelerates the time of reduction of $\operatorname{Ag}(\mathrm{I})$ to metallic $\operatorname{Ag}(0)$ nanoparticles from 7 days to only 30 min. Therefore, photoreduction provides very rapid and efficient formation of AgNPs. This phenomenon may be attributed to the photogeneration of organic radical species from the sensitizer molecule. ${ }^{25,26}$ Figure 3 shows two possible reaction mechanisms for AgNP synthesis using the bioreductant ascorbic acid (Vitamin C) that is contained in the water apple fruit as a model. Ultraviolet radiation from the sun will generate a free radical that has a tendency to react with other compounds, and so the unstable free radical will readily reduce $\mathrm{Ag}(\mathrm{I})$ ion to $\operatorname{Ag}(0)$ as a starting point of AgNPs. The reaction time with sunlight irradiation (Fig. 3b) was significantly faster than those without sunlight irradiation (Fig. 3a). Based on these results, unmodified and freshly prepared AgNPs produced under sunlight irradiation were used for subsequent experiments.

\section{FTIR and SEM analysis of fruit extract and AgNPs}

FTIR measurements were carried out to identify the presence of biomolecules in the water apple fruit extract responsible for reducing $\operatorname{Ag}(\mathrm{I})$ to metallic silver $\operatorname{Ag}(0)$ and stabilizing $\mathrm{AgNPs}$. The FTIR spectra of water apple fruit extract and AgNPs are shown in Fig. 4. For both samples, prominent absorption bands at $3410 \mathrm{~cm}^{-1}$ can be assigned to absorption bands of $\mathrm{O}-\mathrm{H}$ stretching of alcohols and/or phenols. ${ }^{27}$ Absorption bands at $2840 \mathrm{~cm}^{-1}$ are characteristic of $\mathrm{C}-\mathrm{H}$ stretching vibration. In the spectrum of fruit extract, medium bands at 1720, 1675, 1077 and $686 \mathrm{~cm}^{-1}$ may result from the $\mathrm{C}=\mathrm{O}$ stretching, $\mathrm{C}=\mathrm{C}$ ring stretching, $\mathrm{C}-\mathrm{OH}$ bending and $\mathrm{C}-\mathrm{C}$ ring stretching vibration, respectively. ${ }^{27-29}$

Comparison of FTIR spectra of the fruit extract and AgNPs indicating the shift of wavenumbers coupled with the decrease and disappearance of the bands at 3410 and $1077 \mathrm{~cm}^{-1}$ after bioreduction suggest that polyols are mainly responsible for the

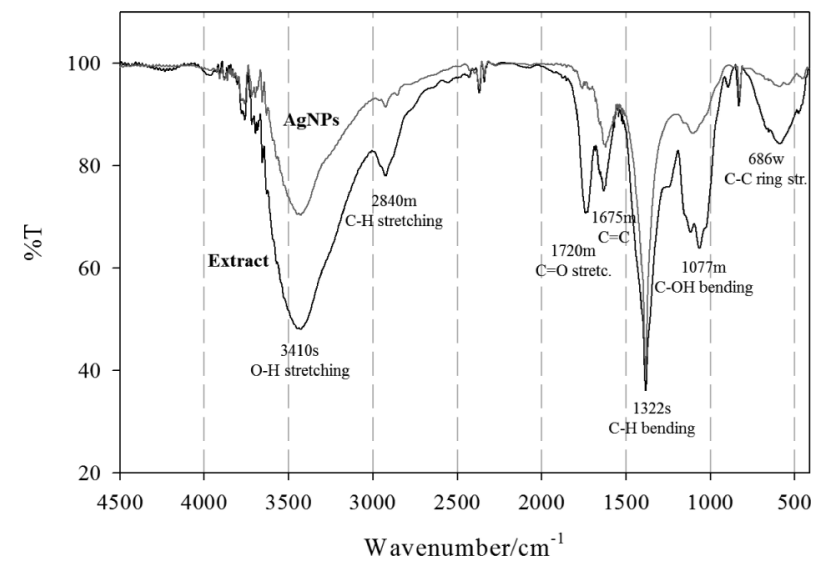

Fig. 4 FTIR spectra of dried powder of water apple fruit extract and AgNPs.

reduction of $\operatorname{Ag}(\mathrm{I}),{ }^{28}$ and also supported by $\mathrm{C}=\mathrm{C}$ and $\mathrm{C}-\mathrm{C}$ ring stretching bands at 1675 and $686 \mathrm{~cm}^{-1}$. The vibrational bands corresponding to the bonds $\mathrm{O}-\mathrm{H}, \mathrm{C}-\mathrm{H}, \mathrm{C}=\mathrm{C}$ ring, $\mathrm{C}-\mathrm{OH}$ and $\mathrm{C}-\mathrm{C}$ ring are derived from water soluble compounds such as ascorbic acid, ${ }^{29}$ as well as flavonoids and polyphenols. ${ }^{30,31}$ These results are in accordance with previous research that show a high content of ascorbic acid and flavonoid in water apple fruit. ${ }^{32,33}$ Hence, it may be inferred that these water-soluble polar compounds are responsible for both reducing $\operatorname{Ag}(\mathrm{I})$ and efficient stabilization or capping of the prepared AgNPs. The spherical shape of AgNPs was confirmed by SEM analysis with an average size of $28.7 \mathrm{~nm}$ (Supporting Information Fig. S1). These results were in accordance with previous results of green synthesized AgNPs that have a peak absorbance at a wavelength of $420 \mathrm{~nm} .{ }^{19,34}$

Colorimetric detection of mercury and analytical performance Unmodified AgNPs produced in the present study were tested for their application as a colorimetric sensor for the detection of $\mathrm{Hg}$ (II) ions. Detection ability of prepared AgNPs was studied for alkali, alkaline earth and transition metal ions (Fig. 5). It was found that the synthesized AgNPs were highly selective to $\mathrm{Hg}$ (II) ions, resulting in the largest absorbance difference, and thus providing a positive indicator for qualitative detection 


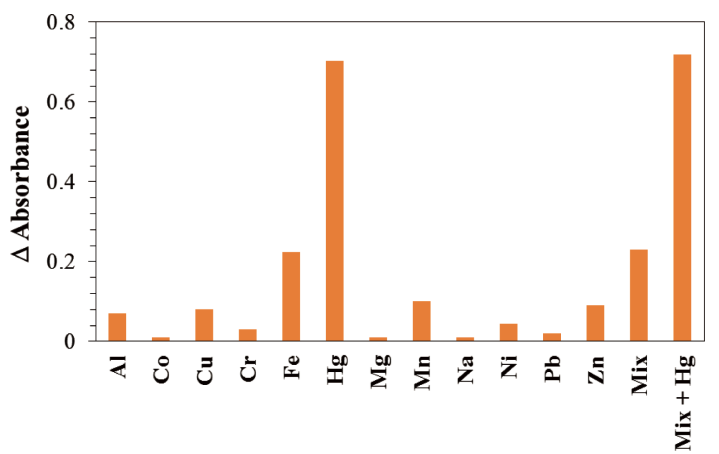

Fig. 5 Change in absorbance of AgNPs colloid in the presence of $60 \mathrm{ppm} \mathrm{Hg}(\mathrm{II})$ and $250 \mathrm{ppm}$ of other metal ions. "Mix" is a mixture of all the metals except $\mathrm{Hg}$.
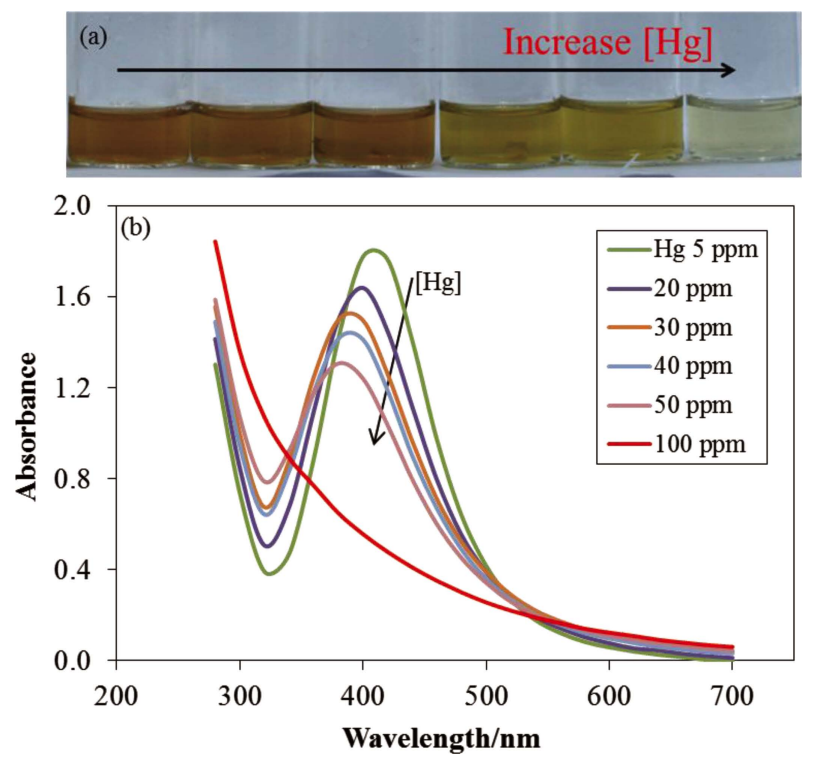

Fig. 6 Digital image of AgNP solution, demonstrating the loss of color with increasing concentration of $\mathrm{Hg}(\mathrm{II})$ ions (a), and UV-visible spectra of AgNP colloidal solution after addition of various concentrations of $\mathrm{Hg}$ (II) ions (b). Successive addition of $\mathrm{Hg}(\mathrm{II})$ decreased the peak absorbance with a significant blue shift.

and prompting further analysis for quantitative application. Although Fe(III) gave a detectable response, generally the effect of alkali, alkaline earth, and other transition metal ions present in the samples, up to $250 \mathrm{ppm}$, was negligible (Fig. 5).

Figure 6a demonstrates the digital image of AgNP colloidal solution after addition of various concentrations of $\mathrm{Hg}$ (II) ions and the corresponding UV-visible spectra (Fig. 6b). Gradual broadening and decrease in peak absorbance of the surface plasmon resonance (SPR) band were observed during successive addition of $\mathrm{Hg}(\mathrm{II})$ ions into AgNPs along with a blue shift from $420 \mathrm{~nm}$ for pure AgNPs to $380 \mathrm{~nm}$ upon addition of $50 \mathrm{ppm}$ $\mathrm{Hg}$ (II) ions (Fig. 6b). These phenomena are known as Mie blue shift, ${ }^{35}$ in which particle diameter was decreasing and the distance between nanoparticles become closer during $\mathrm{Hg}(\mathrm{II})$ reduction by AgNPs, thus increasing their frequencies and at the same time shortening their wavelength. The same phenomena on AgNPs are also reported in previous research, ${ }^{36-38}$ while those of AuNPs were dominated by red shift. ${ }^{10,12}$

The ability of AgNPs to quantitatively detect $\mathrm{Hg}(\mathrm{II})$ was

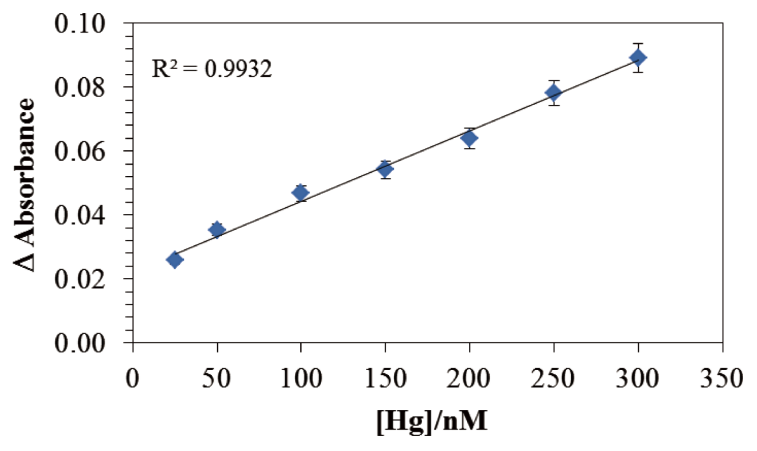

Fig. 7 Linear plot of absorbance intensity difference at wavelength $420 \mathrm{~nm}$ towards $\mathrm{Hg}(\mathrm{II})$ ions concentration.

Table 1 Comparison of limit of detection (LoD) for $\mathrm{Hg}$ (II) analysis using the proposed AgNPs protocol with previously reported method

\begin{tabular}{cccc}
\hline Method & Probe & LoD/M & Reference \\
\hline Ligand- & Rhodamine & $7.7 \times 10^{-8}$ & 46 \\
spectrophotometry & derivative & & \\
& Ruthenium & $1.0 \times 10^{-7}$ & 47 \\
& complexes & $7.5 \times 10^{-7}$ & 47 \\
Nanomaterials- & AuNPs & $5.5 \times 10^{-8}$ & 48 \\
spectrophotometry & & $1.0 \times 10^{-5}$ & 49 \\
& & $2.0 \times 10^{-5}$ & 50 \\
& AgNPs & $8.0 \times 10^{-7}$ & 37 \\
& & $2.2 \times 10^{-6}$ & 38 \\
& & $8.5 \times 10^{-5}$ & Present study \\
\hline
\end{tabular}

demonstrated by adding different concentrations of $\mathrm{Hg}$ (II) to AgNPs and calculating the change in SPR band intensity monitored by UV-visible spectrophotometry. As shown in Figs. 6 and 7, the intensity of the SPR band gradually decreases with the addition of $\mathrm{Hg}$ (II) ions. The absorbance difference increased linearly with the increasing concentration of $\mathrm{Hg}(\mathrm{II})$ ranging from 5 to $100 \mu \mathrm{M}$. The linear regression coefficient $\left(R^{2}\right)$ was 0.9988 with a detection limit of $0.85 \mu \mathrm{M}$ (defined as 3 of the blank, $n=10$ ) making it suitable for quantitative determination of $\mathrm{Hg}$ (II) ions in aqueous solutions at ppb level.

The limit of detection of various $\mathrm{Hg}$ (II) analytical methods are compared to the AgNP protocol here (Table 1). The detection limit of our method is comparable with previously reported values using spectrophotometry coupled with AgNPs, AuNPs, and organic ligands. Among all reported methods, the lowest detection limit was obtained by using $\mathrm{CV}-\mathrm{AFS}^{6}$ and the more sophisticated instruments such as ICP-MS. ${ }^{8}$ In contrast to the proposed AgNP protocol, however, CV-AFS and most of these ICP methods have used initial preconcentration steps of up to 200 times concentration-factor to increase the detection limit. ${ }^{39,40}$ Therefore, the detection limit of the proposed AgNP method could be improved by applying a preconcentration step as an initial procedure. ${ }^{41-43}$ In addition to enriching the concentration of an analyte in final solution, initial preconcentration steps are also useful to remove the high matrix content in samples (e.g. seawater) that interfere with analysis. Further, an advantage of the proposed AgNP method is that it can be optimized for field applications by using digital image colorimetry. 44,45

Finally, we applied the proposed method to real aqueous samples of tap and lake water as shown in Table 2. These 
samples were also spiked with known concentrations of $\mathrm{Hg}(\mathrm{II})$ to check the recovery and precision of the proposed method. Unspiked tap and lake water have no detectable $\mathrm{Hg}$ (II) while the recovery percentages of spiked samples were between 95 to $102 \%$ with a precision better than $5 \%$.

Revisiting the mechanism of $\mathrm{Hg}(\mathrm{II})$ colorimetric detection using AgNPs

Table 3 shows standard reduction potentials for several chemical elements used in AgNP fabrication and colorimetric detection. Ascorbic acid and flavonoid (e.g. quercetin), as biomolecules in fruit extract responsible for the reduction of $\operatorname{Ag}(\mathrm{I})$ to $\operatorname{Ag}(0)$ and formation of AgNPs, have a reduction potential +0.35 and $+0.33 \mathrm{~V}$, respectively. ${ }^{51-53}$ Besides bioreductants, these biomolecules also act as capping agents for AgNP stabilization.

In addition, $\mathrm{Hg}(\mathrm{II})$ has a higher reduction potential than $\mathrm{Ag}(\mathrm{I})$, thus spontaneous redox reaction of $2 \mathrm{Ag}+2 \mathrm{Hg}^{2+} \rightarrow 2 \mathrm{Ag}^{+}+\mathrm{Hg}_{2}{ }^{2+}$ occurs. Oxidation of $\operatorname{Ag}(0)$ to $\operatorname{Ag}(\mathrm{I})$ changes the color of $\mathrm{AgNPs}$ from yellowish-brown to colorless, as observed in the initial colorless $\mathrm{AgNO}_{3}$ solution. This redox reaction is the principle of mercury colorimetric detection by AgNPs. Due to lower reduction potentials than $\operatorname{Ag}(\mathrm{I})$, most of the transition metals, alkali, and alkaline earth metals can not oxidize $\operatorname{Ag}(0)$ of $A g N P s$ to $\mathrm{Ag}(\mathrm{I})$, thus permiting highly selective $\mathrm{Hg}(\mathrm{II})$ analysis.

Based on this reduction potential chemistry, we propose a revised mechanism illustrated in Fig. 8 for $\mathrm{Hg}$ (II) colorimetric detection through redox reaction (upper scheme), and its

Table 2 Recovery test and detection of $\mathrm{Hg}$ (II) in real water samples $(n=3)$

\begin{tabular}{|c|c|c|c|c|}
\hline \multirow{2}{*}{ Sample } & \multicolumn{2}{|c|}{$\mathrm{Hg}(\mathrm{II}), \mathrm{ppm}$} & \multirow{2}{*}{$\begin{array}{c}\text { Recovery, } \\
\%\end{array}$} & \multirow{2}{*}{ RSD } \\
\hline & Added & Found & & \\
\hline \multirow[t]{3}{*}{ Tap water } & 0 & ND & - & - \\
\hline & 2 & $2.03 \pm 0.05$ & 102 & 2.5 \\
\hline & 4 & $3.88 \pm 0.11$ & 97 & 2.8 \\
\hline \multirow[t]{3}{*}{ Lake water } & 0 & ND & - & - \\
\hline & 2 & $1.89 \pm 0.08$ & 95 & 4.2 \\
\hline & 4 & $3.82 \pm 0.15$ & 96 & 3.9 \\
\hline
\end{tabular}

corresponding AgNP aggregation (lower scheme) that takes place without $\mathrm{Hg}(\mathrm{II})$ in the mixture. Although both processes give a decrease in peak absorbance (see Figs. 2 and 5), the oxidation of $\mathrm{Ag}(0)$ by $\mathrm{Hg}(\mathrm{II})$ generates a blue shift of $\mathrm{AgNP}$ absorption band while the aggregation of AgNPs shows the same peak absorbance wavelength (i.e. $420 \mathrm{~nm}$ ). The aggregation of AgNPs that took place after a long period of storage (more than 7 days, in our case) is due to electromagnetic interactions between the particles, inducing nanoparticles agglomeration to a larger size ${ }^{55}$ and thus changing the initial color of AgNPs from yellowish-brown to dark brown, including a small amount of suspended particles in the bottom of the vials as shown in the lower scheme photograph of Fig. 8. After a longer period of storage, all particles aggregated and the solution became clearer with black precipitate. Therefore, it is clear that

Table 3 Standard reduction potentials at $298 \mathrm{~K}^{54}$

\begin{tabular}{lc}
\hline Reduction reaction & $E^{\theta / V}$ \\
\hline $\mathrm{Au}^{+}+\mathrm{e}^{-} \rightarrow \mathrm{Au}$ & +1.69 \\
$\mathrm{Au}^{3+}+3 \mathrm{e}^{-} \rightarrow \mathrm{Au}$ & +1.40 \\
$2 \mathrm{Hg}^{2+}+2 \mathrm{e}^{-} \rightarrow \mathrm{Hg}_{2}^{2+}$ & +0.92 \\
$\mathrm{Hg}^{2+}+2 \mathrm{e}^{-} \rightarrow \mathrm{Hg}$ & +0.86 \\
$\mathrm{Ag}^{+}+\mathrm{e}^{-} \rightarrow \mathrm{Ag}$ & +0.80 \\
$\mathrm{Hg}^{2+}+2 \mathrm{e}^{-} \rightarrow 2 \mathrm{Hg}$ & +0.79 \\
$\mathrm{Fe}^{3+}+\mathrm{e}^{-} \rightarrow \mathrm{Fe}^{2+}$ & +0.77 \\
$\mathrm{Cu}^{2+}+\mathrm{e}^{-} \rightarrow \mathrm{Cu}$ & +0.16 \\
$\mathrm{Fe}^{3+}+3 \mathrm{e}^{-} \rightarrow \mathrm{Fe}$ & -0.04 \\
$\mathrm{~Pb}^{2+}+2 \mathrm{e}^{-} \rightarrow \mathrm{Pb}$ & -0.13 \\
$\mathrm{Ni}^{2+}+2 \mathrm{e}^{-} \rightarrow \mathrm{Ni}$ & -0.23 \\
$\mathrm{Co}^{2+}+2 \mathrm{e}^{-} \rightarrow \mathrm{Co}$ & -0.28 \\
$\mathrm{Fe}^{2+}+2 \mathrm{e}^{-} \rightarrow \mathrm{Fe}$ & -0.44 \\
$\mathrm{Cr}^{3+}+3 \mathrm{e}^{-} \rightarrow \mathrm{Cr}$ & -0.74 \\
$\mathrm{Zn}^{2+}+2 \mathrm{e}^{-} \rightarrow \mathrm{Zn}$ & -0.76 \\
$\mathrm{Mn}^{2+}+2 \mathrm{e}^{-} \rightarrow \mathrm{Mn}$ & -1.18 \\
$\mathrm{Al}^{3+}+3 \mathrm{e}^{-} \rightarrow \mathrm{Al}$ & -1.66 \\
$\mathrm{Ca}^{2+}+2 \mathrm{e}^{-} \rightarrow \mathrm{Ca}$ & -2.87 \\
$\mathrm{Mg}^{2+}+2 \mathrm{e}^{-} \rightarrow \mathrm{Mg}$ & -2.36 \\
$\mathrm{Na}^{+}+\mathrm{e}^{-} \rightarrow \mathrm{Na}$ & -2.71 \\
$\mathrm{~K}^{+}+\mathrm{e}^{-} \rightarrow \mathrm{K}$ & -2.93 \\
$\mathrm{Vitamin}^{\mathrm{C}}$ & +0.35 \\
$\mathrm{Flavonoid}$ & +0.33 \\
\hline
\end{tabular}

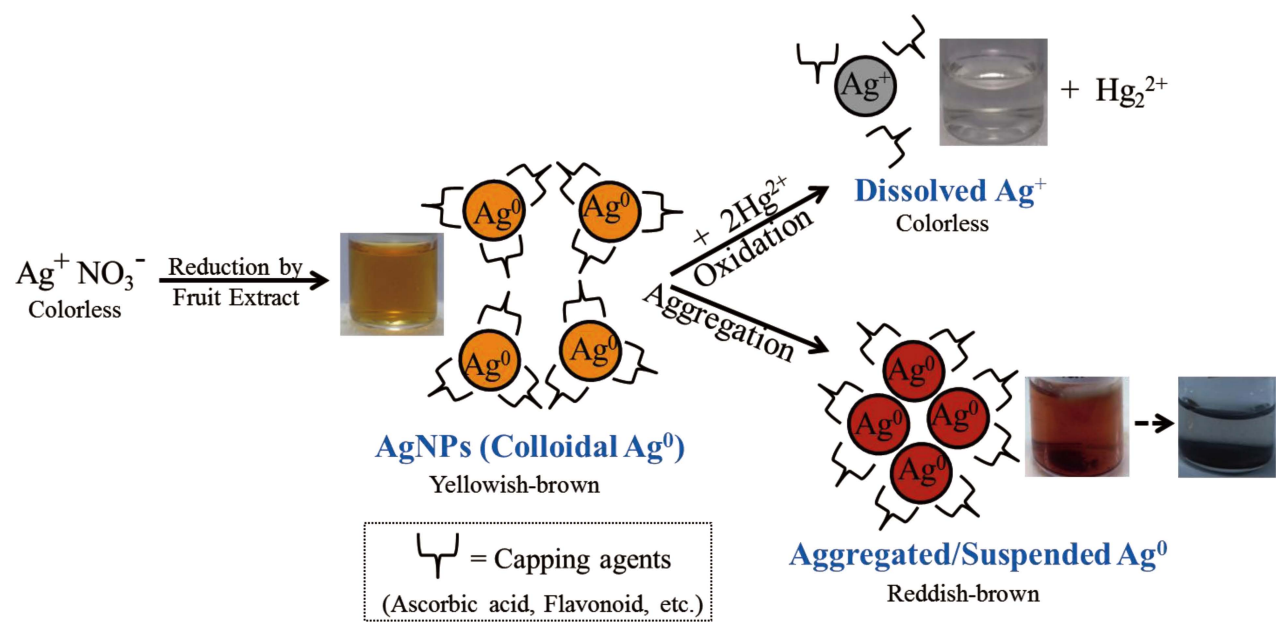

Fig. 8 Proposed schematic illustration of $\mathrm{Hg}(\mathrm{II})$ colorimetric detection using AgNPs through redox reaction (upper scheme) and its corresponding AgNP aggregation (lower scheme). 
colorimetric $\mathrm{Hg}(\mathrm{II})$ detection through a color change from yellowish-brown to colorless has a different mechanism with those of AgNP aggregation. This revised mechanism advances the previously proposed mechanisms. ${ }^{37,56-58}$ However, some mercury colorimetric detection methods using different capping agents or functionalized AgNPs could produce a colored mixture after the addition of $\mathrm{Hg}$ ions, indicating a different reaction mechanism, ${ }^{59}$ as also observed in mercury colorimetric detection using AuNPs. ${ }^{60}$ In these reactions, instead of direct reaction between $\mathrm{Hg}(\mathrm{II})$ ions with $\mathrm{Ag}(0)$ of $\mathrm{AgNPs}$ (or with $\mathrm{Au}(0)$ of AuNPs), the interaction between $\mathrm{Hg}$ ions with capping agents to form the larger size of nanoparticles that lead to aggregation is more dominant. In addition, as shown in Table 3, Au(III) has a very high reduction potential, and thus $\mathrm{Hg}(\mathrm{II})$ can not oxidize $\mathrm{Au}(0)$ of AuNPs to $\mathrm{Au}(\mathrm{III})$ as it occurs on the AgNP system.

\section{Conclusions}

A new low-cost, rapid and green method for colorimetric detection of mercury using silver nanoparticles (AgNPs) was developed. The production of AgNPs can be completed within $30 \mathrm{~min}$ at room temperature with sunlight irradiation assistance. The water-soluble bioactive compounds from Syzygium aqueum fruit extract that act as bioreductants of $\mathrm{Ag}(\mathrm{I})$ to form $\mathrm{AgNPs}$ are determined to most likely be ascorbic acid and flavonoid compounds. The presence of $\mathrm{Hg}$ (II) ions in the mixture will re-oxidize $\operatorname{Ag}(0)$ of $A g N P s$ to $\operatorname{Ag}(\mathrm{I})$ ions and thus change the yellowish-brown color of AgNPs to colorless linearly with the increase of $\mathrm{Hg}(\mathrm{II})$ concentration. By using UV-visible spectrometry, the detection limit of the developed method was found to be $0.85 \mu \mathrm{M}$ with precision better than $5 \%$ for replicate samples analysis. The robust detection protocol of the developed method could be a promising tool for real-time qualitative and quantitative mercury analysis in aquatic environments.

\section{Acknowledgements}

The authors are grateful to the two anonymous reviewers and Associate Editor Dr. Hiroshi Shiigi for their thorough and constructive comments that greatly improved the manuscript. M. L. F acknowledges financial support from the U.S. Fulbright Program, Japan Society for the Promotion of Science (JSPS) and the Indonesia Ministry of Research, Technology and Higher Education (Kemenristek-Dikti).

\section{Supporting Information}

This material is available free of charge on the Web at http:// www.jsac.or.jp/analsci/.

\section{References}

1. T. W. Clarkson, L. Magos, and G. J. Myers, N. Engl. J. Med., 2003, 349, 1731.

2. R. W. Siegler, D. W. Nierenberg, and W. F. Hickey, Hum. Pathol., 1999, 30, 720.

3. M. Harada, Crit. Rev. Toxicol., 1995, 25, 1.

4. D. W. Nierenberg, R. E. Nordgren, M. B. Chang, R. W. Siegler, M. B. Blayney, F. Hochberg, T. Y. Toribara, E. Cernichiari, and T. W. Clarkson, N. Engl. J. Med., 1998, $338,1672$.
5. S. E. Manahan, "Fundamentals of Environmental and Toxicological Chemistry", 2013, CRC Press, New York.

6. H. Bagheri and A. Gholami, Talanta, 2001, 55, 1141.

7. G. A. Cutter, P. Andersson, L. Codispoti, P. Croot, R. Francois, M. C. Lohan, H. Obata, and M. Rutgers, "Sampling and Sample-handling Protocols for GEOTRACES Cruises", 2010, GEOTRACES, Toulouse.

8. H. W. Liu, S. J. Jiang, and S. H. Liu, Spectrochim. Acta, Part B, 1999, 54, 1367.

9. E. Ermakova, M. J. Elizaveta, M. Meyer, V. Arslanov, A. Tsivadze, R. Guilard, and A. Bessmertnykh-Lemeune, Org. Lett., 2013, 15, 662.

10. Y. R. Kim, R. K. Mahajan, J. S. Kim, and H. Kim, ACS Appl. Mater. Interfaces, 2010, 2, 292.

11. H. N. Kim, W. X. Ren, J. S. Kim, and J. Yoon, Chem. Soc. Rev., 2012, 41, 3210.

12. W. Chansuvarn, T. Tuntulani, and A. Imyim, TrAC Trends Anal. Chem., 2015, 65, 83.

13. V. Poornima, V. Alexandar, S. Iswariya, P. T. Perumal, and T. S. Uma, RSC Adv., 2016, 6, 46711.

14. A. Nouailhat, "Introduction to Nanotechnology", 2008, Wiley, New York.

15. K. Vahabi and S. K. Dorcheh, "Biosynthesis of Silver NanoParticles by Trichoderma and Its Medical Applications", 2014, Elsevier, Amsterdam.

16. J. T. Huang, X. X. Yang, Q. L. Zeng, and J. Wang, Analyst, 2013, 138, 5296

17. K. Yoosaf, B. I. Ipe, C. H. Suresh, and K. G. Thomas, J. Phys. Chem., 2007, 111, 12839.

18. H. Li, F. Li, C. Han, Z. Cui, G. Xie, and A. Zhang, Sens. Actuators, B, 2010, 145, 194.

19. D. Karthiga and S. P. Anthony, RSC Adv., 2013, 3, 16765.

20. I. H. Chowdhury, S. Ghosh, M. Roy, and M. K. Naskar, J. Sol-Gel Sci. Technol., 2015, 73, 199.

21. M. L. Firdaus, S. Andriana, Elvinawati, W. Alwi, E. Swistoro, A. Ruyani, and A. Sundaryono, J. Phys.: Conf. Ser., 2017, 817, 012029.

22. P. Anastas and N. Eghbali, Chem. Soc. Rev., 2010, 39, 301.

23. X. Gao, G. Gu, Z. Hu, Y. Guo, X. Fu, and J. Song, Colloids Surf. A, 2005, 254, 57.

24. D. P. Perez, "Silver Nanoparticles", 2010, In-Teh, Croatia.

25. M. Sakamoto, M. Fujistuka, and T. Majima, J. Photochem. Photobiol. C, 2009, 10, 33.

26. E. I. Alarcon, "Silver Nanoparticle Applications", 2015, Springer Int. Pub., Ottawa.

27. H. Schulz and M. Baranska, Vib. Spectrosc., 2007, 43, 13.

28. J. Huang, Q. Li, D. Sun, Y. Lu, Y. Su, X. Yang, H. Wang, Y. Wang, W. Shao, N. He, J. Hong, and C. Chen, Nanotechnology, 2007, 18, 105104.

29. C. Yohannan Panicker, H. Tresa Varghese, and D. Philip, Spectrochim. Acta, Part A, 2006, 65, 802.

30. B. Pawlikowska-Pawlęga, L. E. Misiak, B. Zarzyka, R. Paduch, A. Gawron, and W. I. Gruszecki, Biochim. Biophys. Acta, 2013, 1828, 518.

31. S. D. Silva, R. P. Feliciano, L. V. Boas, and M. R. Bronze, Food Chem., 2014, 150, 489.

32. H. Osman, A. A. Rahim, N. M. Isa, and N. M. Bakhir, Molecules, 2009, 14, 970.

33. T. K. Lim, "Syzygium Aqueum in Edible Medicinal and Non Medicinal Plants", 2012, Springer, Netherlands.

34. M. Annadhasan, T. Muthukumarasamyvel, V. R. Sankar Babu, and N. Rajendiran, ACS Sustain. Chem. Eng., 2014, 2, 887.

35. J. Tiggesbaumker, L. Koller, K. H. Meiwes-Broer, and A. Liebsch, Phys. Rev. A, 1993, 48, 1749. 
36. L. Katsikas, M. Gutiérrez, and A. Henglein, J. Phys. Chem., 1996, 100, 11203 .

37. S. Bothra, J. N. Solanki, and S. K. Sahoo, Sens. Actuators, $B, \mathbf{2 0 1 3}, 188,937$.

38. K. Farhadi, M. Forough, R. Molaei, S. Hajizadeh, and A. Rafipour, Sens. Actuators, B, 2012, 161, 880.

39. J. C. de Wuilloud, R. G. Wuilloud, M. F. Silva, R. A Olsina, and L. D. Martinez, Spectrochim. Acta, Part B, 2002, 57, 365.

40. Y. Li and B. Hu, Spectrochim. Acta, Part B, 2007, 62, 1153.

41. M. L. Firdaus, P. Darti, W. Alwi, E. Swistoro, A. Sundaryono, A. Ruyani, AIP Conference Proceedings, 2015, 1677, 110003.

42. M. L. Firdaus, K. Norisuye, T. Sato, S. Urushihara, Y. Nakagawa, S. Umetani, and Y. Sohrin, Anal. Chim. Acta, 2007, 583, 296.

43. A. Suzuki, H. Obata, A. Okubo, and T. Gamo, Mar. Chem., 2014, 166, 114.

44. P. Masawat, A. Harfield, N. Srihirun, and A. Namwong, Anal. Lett., 2016, 50, 173.

45. M. L. Firdaus, W. Alwi, F. Trinoveldi, I. Rahayu, L. Rahmidar, and K. Warsito, Proc. Environ. Sci., 2014, 20, 298.

46. H. El Kaoutit, P. Estevez, F. C. Garcia, F. Serna, and J. M. Garcia, Anal. Methods, 2013, 5, 54.

47. E. Coronado, J. R. Galan-Mascaros, C. Marti-Gastaldo, E. Palomares, J. R. Durrant, R. Villar, M. Gratzel, and M. K.
Nazeeruddin, J. Am. Chem. Soc., 2005, 127, 12351.

48. X. Yang, H. Liu, J. Xu, X. Tang, H. Huang, and D. Tian, Nanotechnology, 2011, 22, 275503.

49. S. Boopathi, S. Senthilkumar, and K. L. Phani, J. Anal. Methods Chem., 2012, 1, 348965.

50. S. Si, A. Kotal, and T. K. Mandal, J. Phys. Chem. C, 2007, $111,1248$.

51. T. Matsui, Y. Kitagawa, M. Okumura, and Y. Shigeta, $J$. Phys. Chem. A, 2015, 119, 369.

52. W. F. Hodnick, E. B. Mllosavljević, J. H. Nelson, and R. S. Pardini, Biochem. Pharmacol., 1998, 37, 2607.

53. S. V. Jovanovic, S. Steenken, Y. Hara, and M. G. Simic, J. Chem. Soc. Perkin Trans., 1996, 2, 2497.

54. P. Atkins and J. de Paula, "Physical Chemistry", 2009, W. H. Freeman, Oxford.

55. L. Zhao, L. L. Zhao, K. L. Kelly, K. L. Kelly, G. C. Schatz, and G. C. Schatz, J. Phys. Chem. B, 2003, 107, 7343.

56. M. Annadhasan and N. Rajendiran, RSC Adv., 2015, 5, 94513.

57. Y. Wang, F. Yang, and X. Yang, ACS Appl. Mater. Interfaces, 2010, 2, 339.

58. M. Nidya, M. Umadevi, and B. J. M. Rajkumar, Spectrochim. Acta, Part A, 2014, 133, 265.

59. J. Duan, H. Yin, R. Wei, and W. Wang, Biosens. Bioelectron., 2014, 57, 139.

60. W. Chansuvarn and A. Imyim, Microchim. Acta, 2012, 176, 57. 